\title{
Pancreatic Duct Glands Are Distinct Ductal Compartments That React to Chronic Injury and Mediate Shh-Induced Metaplasia
}

\section{Citation}

Strobel, Oliver, David E. Rosow, Elena Y. Rakhlin, Gregory Y. Lauwers, Amanda G. Trainor, Janivette Alsina, Carlos Fernández-Del Castillo, Andrew L. Warshaw, and Sarah P. Thayer. 2010. Pancreatic duct glands are distinct ductal compartments that react to chronic injury and mediate shh-induced metaplasia. Gastroenterology 138(3): 1166-1177.

\section{Published Version}

doi:10.1053/j.gastro.2009.12.005

\section{Permanent link}

http://nrs.harvard.edu/urn-3:HUL.InstRepos:12490653

\section{Terms of Use}

This article was downloaded from Harvard University's DASH repository, and is made available under the terms and conditions applicable to Other Posted Material, as set forth at http:// nrs.harvard.edu/urn-3:HUL.InstRepos:dash.current.terms-of-use\#LAA

\section{Share Your Story}

The Harvard community has made this article openly available.

Please share how this access benefits you. Submit a story.

Accessibility 


\title{
Pancreatic Duct Glands are Distinct Ductal Compartments that React to Chronic Injury and Mediate Shh-induced Metaplasia
}

\author{
OLIVER STROBEL ${ }^{\star} \S$, DAVID E. ROSOW ${ }^{\star}$, ELENA Y. RAKHLIN ${ }^{\star}$, GREGORY Y. LAUWERS $¥$, \\ AMANDA G. TRAINOR ${ }^{\star}$, JANIVETTE ALSINA $^{*}$, CARLOS FERNÁNDEZ-DEL CASTILLO ${ }^{*}$, \\ ANDREW L. WARSHAW ${ }^{*}$, and SARAH P. THAYER ${ }^{*}$ \\ *Department of Surgery, Massachusetts General Hospital and Harvard Medical School, Boston, \\ Massachusetts \\ ¥Department of Pathology, Massachusetts General Hospital and Harvard Medical School, Boston, \\ Massachusetts \\ $\S$ Department of General Surgery, University of Heidelberg, Heidelberg, Germany
}

\section{Abstract}

Background \& Aims-Pancreatic intraepithelial neoplasia (PanIN) are pancreatic cancer precursor lesions of unclear origin and significance. PanIN aberrantly express sonic hedgehog (Shh), an initiator of pancreatic cancer, and gastrointestinal mucins. The majority of PanIN are thought to arise from ducts. We identified a novel ductal compartment that is gathered in glandlike outpouches (pancreatic duct glands, PDG) of major ducts and characterized its role in injury and metaplasia.

Methods-The ductal system was analyzed in normal pancreata and chronic pancreatitis in humans and mice. Anatomy was assessed by serial H\&E sections and scanning electron microscopy of corrosion casts. Expression of mucins and developmental genes and proliferation were assessed by immunohistochemistry or RT-qPCR. Effects of Shh on ductal cells were investigated by exposure to Shh in vitro and transgenic misexpression in vivo.

Results-Three-dimensional analysis revealed blind-ending outpouches of ducts in murine and human pancreata. These PDG are morphologically and molecularly distinct from normal ducts; even in normal pancreata they display PanIN and metaplastic features such as expression of Shh and gastric mucins. They express other developmental genes, such as $P d x-1$ and Hes-1. In injury, Shh is upregulated along with gastric mucins. Expansion of the PDG compartment results in a mucinous metaplasia. Shh promotes this transformation in vitro and in vivo.

Conclusions-PDG are a distinct gland-like mucinous compartment with a distinct molecular signature. In response to injury PDG undergo a Shh-mediated mucinous gastrointestinal

\footnotetext{
(c) 2009 The American Gastroenterological Association. Published by Elsevier Inc. All rights reserved.

*Correspondence: Sarah P. Thayer, M.D., Ph.D., Department of Surgery, Massachusetts General Hospital, 15 Parkman Street, WACC 460, Boston, MA 02114, USA. Phone: (617) 726 0624, Fax: (617) 726 0630, sthayer@partners.org.

Author contributions: study concept and design: O.S., C.F.C, A.L.W., S.P.T., data acquisition: O.S., D.E.R., E.Y.R., A.G.T, J.A., S.P.T., data analysis and interpretation: O.S., G.Y.L., C.F.C, A.L.W., S.P.T., drafting and critical revision of manuscript: O.S., G.Y.L., C.F.C, A.L.W., S.P.T

None of the authors have a conflict of interest.

Publisher's Disclaimer: This is a PDF file of an unedited manuscript that has been accepted for publication. As a service to our customers we are providing this early version of the manuscript. The manuscript will undergo copyediting, typesetting, and review of the resulting proof before it is published in its final citable form. Please note that during the production process errors may be discovered which could affect the content, and all legal disclaimers that apply to the journal pertain.
} 
metaplasia with PanIN-like features. PDG may provide a link between Shh, mucinous metaplasia and neoplasia.

\section{Background}

Chronic injury is linked to carcinogenesis in several tumors, including pancreatic cancer. Chronic pancreatitis (CP) and pancreatic cancer share the presence of pancreatic intraepithelial neoplasia (PanIN), believed to be cancer precursors. ${ }^{1}$ Although the morphology and molecular signature of PanIN and cancer make a ductal origin likely, their cellular origin is still under debate; recent studies suggest that at least a part of the lesions are of acinar origin. ${ }^{2-5}$ The ductal epithelium itself is poorly characterized and often discussed as a single population of cells. Better characterization of ductal compartments may advance our understanding of diseases such as $\mathrm{CP}$ and pancreatic cancer. One main characteristic defining PanIN is an increased, aberrant mucin expression, suggesting mucinous metaplasia as an early step in carcinogenesis. Little is known about the origin, onset and underlying molecular events of this metaplasia.

The same genes involved in embryonic development appear to play a role in regeneration and, through inappropriate regulation, in metaplasia and ultimately neoplasia. ${ }^{6,7} \mathrm{Pdx}-1$ is important for early pancreatic development and involved in regeneration. ${ }^{6,8-10}$ Notch signaling is involved in pancreatic development, regeneration and neoplasia; its effector Hes-1 is discussed as a marker of progenitor cells. ${ }^{6,11-13}$ Sonic hedgehog (Shh) inhibits pancreatic development and directs the foregut mesoderm toward a gastrointestinal (GI) fate. ${ }^{14}$ Shh is aberrantly expressed in PanIN and pancreatic adenocarcinoma, and contributes to carcinogenesis. ${ }^{15}$ In contrast to Pdx-1 and Hes-1, Shh has not been previously identified in the normal pancreas. ${ }^{14,15}$

Identification of Shh and gastric mucins called our attention to small outpouches of major ducts in normal pancreata. Here we identify and characterize this novel ductal compartment which is gathered in outpouches, pancreatic duct glands (PDG). PDG have a unique molecular signature distinct from the pancreatic epithelium: they retain expression of gastric mucins and Shh. Additionally, PDG express other developmental genes, such as Pdx-1 and Hes-1, which are also expressed in other regions of the pancreas. In response to chronic injury, PDG upregulate developmental genes and proliferative rates and undergo a Shhmediated mucinous metaplasia. This response suggests PDG may play a role in pancreatic duct protection, renewal, metaplasia, and possibly neoplasia.

\section{Materials and Methods}

Human Samples were collected and analyzed in accordance with IRB approval. Histologically normal control pancreata $(n=8)$ were obtained from $n=6$ organ donors $(21-48$ years) or from patients who underwent pancreaticoduodenectomy for extrapancreatic disease $(\mathrm{n}=2$, one duodenal cancer and one bile duct cancer). Histologically confirmed human CP samples were obtained from pancreaticoduodenectomy specimens at the MGH $(n=10)$.

Mouse Samples-All experiments were approved by the MGH Subcommittee on Research Animal Care. Healthy CD-1 mice (Charles River) served as controls $(n=10)$. Acute pancreatitis was induced in CD-1 mice of either sex, by 6 hourly intraperitoneal injections of $50 \mu \mathrm{g} / \mathrm{kg}$ cerulein (Sigma). Chronic pancreatic injury ${ }^{2,16}$ was induced by 3 series of injections per week for periods of $3(n=10), 6(n=4), 10(n=3)$, and $18(n=2)$ weeks in CD-1 mice and Ptch1-LacZ reporter mice. Pancreatawere harvested 72 hours after the last injection using a microsurgical microscope (Codman Microsystems, magnification 15-45x). Proliferation was assessed by immunostaing after in vivo pulse labeling by intraperitoneal 
injection of bromodeoxyuridine (BrdU, Sigma) at $1 \mathrm{mg} / 10 \mathrm{~g}$ body weight $2-3 \mathrm{hrs}$ prior to harvesting. Positive and negative nuclei were counted in two high-power fields per sample in 4 samples per group.

Shh-misexpressing Transgenic Mice-Pdx-Shh mice were generated by pronuclear injection as previously described. ${ }^{15}$

\section{Histology and Immunohistochemistry}

Specimens were fixed overnight in $4 \%$ paraformaldehyde or $10 \%$ formalin/PBS. Histologic analysis was performed on 3-4 $\mu \mathrm{m}$ paraffin-embedded sections by an experienced GI pathologist (G.Y.L.). Mucins were detected using Alcian blue (pH 2.8) and periodic acidSchiff stains. Primary antibodies and conditions for immunohistochemistry are specified in Supplementary Table 1. Endogenous peroxidase activity was quenched by $3 \% \mathrm{H}_{2} \mathrm{O}_{2}$. Biotinylated secondary antibodies were applied at 1:1000 dilution. Proteins were visualized by brown pigmentation using DAB (Zymed). Slides were counterstained with hematoxylin.

Ptch1 expression was identified in Ptch1-LacZ animals by staining with the LacZ substrate 5-bromo-4-chloro-3-indolyl $\beta$-D-galactoside (X-Gal) (Sigma). Specimens were prefixed for $75-90 \mathrm{~min}$ in $4 \%$ paraformaldehyde at $4{ }^{\circ} \mathrm{C}$, washed in buffer and incubated in X-Gal solution containing protease inhibitors at room temperature for 24 hours. Specimens were post-fixed in $4 \%$ paraformaldehyde for 4 hours, dehydrated, paraffin-embedded, sectioned and counterstained with nuclear-fast red. Age-matched wild-type littermates were negative controls.

\section{Casts of the Ductal System}

Corrosion casts of the ductal system of five murine pancreata and one human pancreas from organ donation were obtained by intraductal infusion of the casting medium (Mercox Resin, Ladd Research Industries, diluted with 10\% methyl methacrylate monomer). The resin-filled tissue was immersed in hot water $\left(60^{\circ} \mathrm{C}\right)$ for one hour for resin curing. Tissue was then removed by maceration in alternating rinses of $5-10 \% \mathrm{KOH}$ and hot water, cleaned in formic acid, washed in distilled water and lyophilized. Casts were imaged by light microscopy and then sputter-coated (Hummer V, Anatech) with gold/platinum for scanning electron microscopy (SEM) with a LEO 1450VP scanning electron microscope (Carl Zeiss) at $15 \mathrm{kV}$.

\section{Quantitative Real-time PCR}

RNA was extracted (RNA Isolation Kit, Ambion) from tissues stored at $-20^{\circ} \mathrm{C}$ in RNAlater (Ambion). One-step multiplex TaqMan Real-time RT-PCR was performed using an ABI 7700 Sequence Detector system. Expression of SHH, IHH, DHH, PTCH, SMO, GLI1 and GLI2 was evaluated using 18S RNA as internal control. Probes and primers were designed to span exon-exon junctions to avoid amplification of genomic DNA. The thermal cycler conditions were: Reverse transcription for 30 minutes at $48^{\circ} \mathrm{C}$, initial activation step for 10 minutes at $95^{\circ} \mathrm{C}$, followed by 40 cycles of denaturation for 15 seconds at $95^{\circ} \mathrm{C}$ and annealing/extension for 60 seconds at $60^{\circ} \mathrm{C}$. Fluorescence data were collected during annealing and analyzed using SDS1.7 software (Applied Biosystems). Relative gene expression was determined based on corresponding $\mathrm{Ct}$ (threshold cycle) values.

\section{In vitro SHH experiments}

Human pancreatic ductal epithelial (HPDE) cells ${ }^{17,18}$ were cultured in keratinocyte serumfree media supplemented with bovine pituitary extract and human epidermal growth factor (GIBCO, Invitrogen). Cells were exposed to 0, 5, 10, or $20 \mathrm{nM}$ recombinant human $\mathrm{SHH}$ 
(R\&D Systems) in culture media. Media was changed every 48 hrs. After 8 days (192 hrs), cells were stained for PAS and total RNA was harvested for analysis by RTq-PCR.

\section{Statistics}

Statistical analysis was performed using GraphPad Prism4 software. Proliferation in PDG vs. main ducts was compared using 2-way contingency table analyses and Chi-square and Fisher exact tests. Quantitative gene expression is given as -fold expression over mean expression in normal pancreata or control cells. The Wilcoxon matched pairs test was used for comparison of main duct versus parenchymal tissue. P-values are two-tailed.

\section{Results}

\section{Pancreatic Ducts Have Blind-ending Outpouches: Pancreatic Duct Glands}

H\&E stains of serial sections were used to morphologically assess the normal pancreatic ductal system in healthy mice and normal human pancreata. In both mice and humans, an epithelial compartment morphologically distinct from the normal ductal epithelium was identified. This unique compartment appears as either gland-like outpouches or coiled structures residing within the mesenchyme surrounding larger ducts (Fig. 1). The epithelial lining of these structures is composed of cells with basally located nuclei and abundant supranuclear cytoplasm. Comparison of proximal (near the papilla) and peripheral ducts revealed that these branches/outpouches are more frequent in proximal ducts. Histologic evaluation of $3 \mu \mathrm{m}$ serial sections suggested that these structures are blind-ending outpouches rather than branches (supplemental Fig. 1\&2).

To reliably distinguish blind-ending "glands" from small branch ducts based on 3dimensional information, we used SEM of ductal corrosion casts. We obtained detailed, high-resolution casts of the entire ductal system of five mice and one human (Fig. 2 A\&B). Ramification in both the human and rodent pancreas is hierarchical: large interlobular ducts branch off the main duct and into smaller interlobular ducts, which then branch again into smaller ducts (Fig. 2 C\&D). Multiple small branches of large ducts do not exist. SEM directly confirmed the presence of outpouches in the ductal system of mice and humans (Fig. 2E). The distribution of these outpouches is not uniform: in mice, outpouches are frequently found in the biliopancreatic duct, in the main duct draining the left part of the pancreas, and in proximal interlobular ducts. Outpouches are less frequently observed in small pancreatic ducts. Interestingly, outpouches are often located near ductal branching sites (Fig. 2E). Overall, this distribution results in a proximal pattern with a decreasing frequency from large toward small ducts. The distribution of outpouches in humans is similar, but they are observed less frequently than in rodents. Outpouches can have a single lumen or display a complex arrangement of several sac-like dilatations (lower panels in Fig. 2E).

These SEM data confirm the existence of a unique gland-like ductal compartment which we will henceforth call Pancreatic Duct Glands (PDG). The existence of specialized ductassociated glands raises the question of their function and their role in pancreatic disease.

\section{PDG Undergo Hyperplasia in Response to Chronic Injury}

The entire ductal system was assessed for morphologic changes induced by a wellestablished murine model of chronic pancreatic injury. ${ }^{2,16}$

Chronic injury for 6 or more weeks results in severe changes in both ductal epithelium and mesenchyme; PDG change in both frequency and morphology (Fig. 3). Controls have a thin mesenchymal wall surrounding the proximal ducts, with few PDG. PDG are small, often 
have a single lumen, and only rarely display several glandular units (Fig. 3A). In response to chronic injury the ductal mesenchyme thickens. PDG increase in both number and size and display an often complex architecture, with branching and folds as well as features of atypia such as papillations and nuclear pseudostratification (Fig. 3B). The epithelium takes on a more mucinous appearance. These PanIN-like features are more frequently found in PDG of larger ducts, but can be detected scattered in peripheral ducts.

Thus, in response to chronic injury PDG appear to undergo hyperplasia and develop a mucinous metaplasia with PanIN-like features.

\section{PDG Retain GI Mucins and Are a Source of GI Metaplasia}

Metaplastic ductal lesions, including PanIN and cancer, frequently express GI markers. ${ }^{19,20}$ Normal pancreatic ducts express $\mathrm{PAS}^{+}$, but not Alcian-blue ${ }^{+}$mucins. In contrast, metaplastic lesions frequently express Alcian blue ${ }^{+}$mucins and gastric Muc5ac, which is considered an early sign of metaplasia. ${ }^{19,21}$ To determine whether PDG are a possible source, their mucin expression patterns were characterized in normal and injured pancreata and compared to normal pancreatic and GI epithelium.

Results in mice (Fig. 4) closely mirror results in humans (Suppl. Fig. 3). $\mathrm{PAS}^{+}$mucins and Muc1 are present at the luminal membrane in the entire ductal system (Fig. 4A). However, only PDG exhibit intense cytoplasmic PAS staining, suggesting a function in mucin secretion (Fig. 4B). Moreover, PDG express Alcian blue ${ }^{+}$mucins, including mucins which are normally found in the deep part of the gastric pyloric glands, namely Muc6 (Fig. 4 $\mathrm{B} \& \mathrm{E})$. Thus, PDG in the normal pancreas express mucins which so far have been considered metaplastic. In response to chronic injury, PDG appear hyperplastic, and exhibit not only an upregulation and expansion of Muc6 but also de novo expression of Muc5ac, resulting in a mucinous metaplasia (Fig. 4 C\&D). Whereas the gastric Muc5ac is frequently found in PDG in response to injury, de novo expression of the intestinal Muc2 is observed only rarely.

Mucin expression patterns confirm that PDG are distinct from the rest of the pancreatic ductal epithelium and undergo a progressive mucinous metaplasia which closely recapitulates features of the gastric pyloric epithelium.

\section{PDG Retain and Upregulate Developmental Pathways, Including Shh}

The pancreatic ductal epithelium has a low turnover rate, and little is known about its regeneration. In many tissues regeneration and the formation of metaplasia are controlled by the same genes that direct tissue differentiation during development. ${ }^{7}$ Our next step, therefore, was to analyze PDG for the expression of developmental genes known to play a key role in pancreatic development and disease. Expression of Hh pathway genes as well as Pdx-1 and Hes-1 was analyzed in controls and in response to chronic injury in the same mice used previously. Additionally, proliferative activity was analyzed by Ki-67 expression or BrdU incorporation.

Normal Pancreas-In contrast to previous studies, which had not identified Shh in normal pancreas, Shh was identified specifically and only in PDG (Fig. 5A). In Ptch1-LacZ animals, the Hh receptor Ptch1 was identified in the ductal mesenchyme surrounding PDG. The Ptch2 receptor is co-expressed with Shh in the epithelium of PDG and in single cells of the normal ductal epithelium. Pdx-1 is expressed predominantly in PDG, but can also be found in the epithelial lining of the main lumen. Hes-1, which is known to be expressed in peripheral ducts and centroacinar cells, ${ }^{12}$ is predominantly expressed in PDG in larger ducts (Fig. 5A). 
Chronic Injury-In response to chronic injury, all three pathways appear upregulated with different patterns (Fig. 5B\&C). Shh appears to be upregulated, but remains specific to mucinous metaplastic PDG. Additionally, Shh was focally observed in mucinous lesions located in the periphery. Ptch1 expression was expanded in the fibrotic ductal mesenchyme, and Ptch2 expression in PDG and in the main ductal epithelium. Expression of both Pdx-1 and Hes-1 was expanded throughout the ductal epithelium, but Pdx-1 maintained a more proximal, Hes-1 a more peripheral predominance. All developmental genes remained expressed in severely metaplastic PDG (Fig. 5C).

Proliferation-In contrast to the GI epithelium, the pancreatic ductal epithelium has a low turnover rate. In controls proliferation is only occasionally detected in the ductal epithelium, including PDG (Fig. 5D). In response to injury, proliferation was predominantly localized to PDG. In ducts with pronounced metaplasia, Ki-67 demonstrated proliferative activity predominantly in PDG and in the deep portion of mucosal folds and was lost toward the surface. In response to injury, $\mathrm{BrdU}^{+}$or $\mathrm{Ki}-67^{+}$nuclei were significantly more frequent in PDG compared to the ductal lining ( $\mathrm{p}<0.001$; Odds Ratio 6.6 (3.9-11.0) for acute injury and 14.0 (8.2-24.1) for chronic injury).

Results in human pancreata (supplemental Fig. 4) reflect the observations made in the mouse.

\section{Evidence for Peripheral PDG}

To search for peripheral PDG, the markers specific for the PDG compartment, Shh, Alcian blue and gastric mucins, were assessed in peripheral ducts of control mice and mice with chronic injury. None of these markers could be identified in small pancreatic ducts in controls; but outpouches co-expressing these markers could be identified in the thickened mesenchyme of both small interlobular (Fig 6A) and intralobular ducts (Fig. 6B) in response to chronic injury, suggesting that their presence is likely too small to be identified in a nonhyperplastic state.

\section{Shh Misdirects Pancreatic Ducts Toward a GI Mucinous Metaplasia}

In development, Shh directs the foregut mesoderm toward a GI fate; in the adult, Shh appears to promote gastric gland differentiation, ${ }^{22}$ and has been identified as an early mediator of pancreatic carcinogenesis. ${ }^{15}$ The strict co-localization of Shh and gastric-type mucinous metaplasia in PDG led us to hypothesize that inappropriate upregulation of Shh may be responsible for the metaplasia seen in chronic injury by directing the pancreatic ductal epithelium towards a gastric fate. HPDE cells transfected with the Hh effector Gli1 upregulate foregut markers ${ }^{23}$. We aimed to determine whether the pancreatic ductal epithelium is directly responsive to the ligand Shh and whether increased levels of Shh can drive a gastric mucinous metaplasia.

HPDE cells ${ }^{17,18}$ were exposed to recombinant Shh and analyzed for Ptch and mucin expression. HPDE exposed to recombinant SHH for 8 days showed a phenotypical change with enhanced mucin expression compared to control cells (Fig. 7A). Quantitative RT-PCR revealed that HPDE cells express the Hh receptor and downstream gene PTCH2 and upregulate this expression in response to Shh exposure, demonstrating Hh pathway activation. Moreover, HPDE cells upregulate expression of the gastric mucins MUC6 and especially MUC5ac (Fig. 7A). Thus, HPDE cells are responsive to the ligand Shh and undergo gastric mucinous transformation after Hh pathway activation in vitro.

To analyze whether Shh has similar effects in vivo, we evaluated the effects of engineered Shh misexpression on phenotype and mucin expression of pancreatic ducts. Analysis of 
pancreata from Pdx-Shh transgenic mice demonstrated that the ductal epithelium first has a non-mucinous appearance and secondarily develops a mucinous metaplasia. Again, this Shh-mediated metaplasia is characterized by expression of gastric mucins, such as Muc5ac (Fig. 7B).

In vitro and in vivo results demonstrate that the adult pancreatic ductal epithelium is responsive to Shh signalling and that enhanced levels of Shh are sufficient to drive a GI mucinous metaplasia. Thus PDG-derived Shh may drive mucinous metaplasia and PanINlike formation in pancreatic disease.

\section{PDG Display SHH Upregulation and Metaplasia in Human Chronic Pancreatitis}

To assess the relevance of our findings to human disease, we analyzed Shh expression and metaplastic changes in human pancreata.

SHH was not detected in peripheral pancreatic ducts, acini or islets of normal human pancreata $(n=8)$. However, SHH is expressed in PDG (Fig. 8A). In CP (n=6) SHH appears upregulated. In all pancreata evaluated SHH was aberrantly expressed at a much higher level in an expanded, morphologically hyperplastic epithelium exhibiting increased mucin expression and cellular atypia, features of PanIN (Fig. 8A). Comparison of proximal (Fig. $8 \mathrm{~A}$ ) to peripheral ducts (Fig. $8 \mathrm{~B}$ ) revealed that these changes are present focally throughout the ductal epithelium but have a proximal predominance. SHH expression in peripheral ducts was always co-localized with mucinous metaplasia or atypia.

RTq-PCR was performed for the Hh pathway (Fig. 8C). In normal pancreata (n=6) all Hh transcripts were detected at a low level. In $\mathrm{CP}(\mathrm{n}=10)$, the entire pathway, including ligands, receptors, and transcription factors, was upregulated. Although all three ligands were identified, SHH had the highest upregulation. Expression of Shh and its pathway members is found at much higher levels in biopsies of proximal ducts compared to matched peripheral biopsies. Whereas by immunostaining the enhanced expression of Shh appears to be localized to the metaplastic epithelium, upregulation of the downstream genes may also involve the mesenchyme.

Together immunostaining and RT-PCR confirm that SHH remains expressed in the PDG compartment in human pancreata and suggest that in the human SHH has effects similar to those shown in mice.

\section{Conclusions}

The pancreatic ductal epithelium is a heterogeneous group of cells. We present evidence that this epithelium harbors a specialized compartment, pancreatic duct glands. In its normal state this compartment retains expression of developmental markers, including Shh, and is a site of production of gastric-type mucins. In response to chronic injury, the compartment is a source of a Shh-mediated gastric mucinous metaplasia.

Specialized mucin-producing glands in the pancreas were first noted in the 1960s. ${ }^{24}$ In the 1980s Bock et al. investigated secretory cells within pancreatic ducts by electron microscopy and by their histochemical staining pattern. They found that mucin-producing cells were gathered in mucosal folds, forming endo-epithelial glands which they called "duct glands. ${ }^{25-27}$ However their anatomic character as blind-ending structures could not be conclusively elucidated. This compartment and its role in injury have not been further analyzed until now. 
In the present study, SEM of ductal corrosion casts allowed to directly demonstrated in both rodents and humans that these structures are blind-ending outpouches. PDG have a greater prevalence in rodents than in humans, consistent with inter-species variability in the frequency of mucin-producing cells. ${ }^{24}$ The predominant cells in these glands are mucinproducing and have basally located nuclei and abundant supranuclear cytoplasm. This morphology resembles PanIN-1A. Because PanIN-1A may be seen in otherwise normal pancreata, the original PanIN classification acknowledges the possible existence of nonneoplastic "lesions" in normal pancreata, referred to as PanIN/L- $1 \mathrm{~A}^{1}$. Our data suggest that PDG may account for at least a subset of such early PanIN and may be the origin of later PanIN.

The existence of "pancreatic duct glands" raises the question of their function. Clearly, they are a specific site of mucin production which serves for mucosal protection. Because ductal cell turnover in the normal pancreas is low, studies investigating its renewal are difficult and little is known about renewal of the pancreatic ductal epithelium. In a study of the ductal epithelium in human CP, expression patterns of growth factors identified a specialized epithelium which buds off the main lumen and was suggested to play a role in repair. ${ }^{28}$ In rodent models of pancreatic injury Pdx-1 is induced in the main duct and "small evaginations". ${ }^{10,29}$ PDG express and upregulate several of the genes that mark progenitor cells in intestinal crypts, Shh, Pdx-1 and Hes-1. Although the proliferation data and the expression of developmental markers show that, unlike intestinal crypts, PDG are not the exclusive site of cells likely to be involved in epithelial renewal, their predominance in PDG suggests that PDG contribute to epithelial renewal and repair.

Dysregulation of mechanisms involved in regeneration and repair can lead to metaplasia and ultimately neoplasia. ${ }^{7}$ In the pancreas, the Hh pathway is involved in regeneration. ${ }^{30}$ Its ligand Shh has been identified as an initiator of neoplasia. ${ }^{15}$ Most recently Shh has been identified in pancreatic cancer stem cells. ${ }^{31,32}$ The finding that Shh remains expressed in PDG, that exhibit features of "metaplasia" may explain prior observations of Shh and GI marker expression in early PanIN even in the absence of other signs of atypia or alterations of other cancer-related genes. The finding that the PDG compartment is particularly prone to Shh-mediated GI metaplasia in response to injury suggests both a source and mechanism of metaplasia in the diseased pancreas. Interestingly, injured human and mouse pancreata exhibit a highly organized gastric-type metaplasia that closely mirrors the mucin expression pattern of the pylorus. Although this is speculative, we may propose that Shh-mediated metaplasia in the pancreas may play a similar role to that described for CDX-1-mediated intestinal metaplasia in the stomach and esophagus, and may, like Barrett's metaplasia, ${ }^{33,34}$ be associated with the risk for cancer.

Recent attention has focused on the importance of paracrine Hh signaling for desmoplasia and pancreatic cancer progression..$^{35,36}$ In a recent study by Tian et al. Hh ligands were expressed in the epithelium but only the stromal compartment was found to be able to transduce downstream pathway activity during pancreatic carcinogenesis. ${ }^{37}$ Similar to our study, Tian et al. used the Ptch1-LacZ mouse and - mirroring our results - Hh pathway activity was reported exclusively in the mesenchyme ${ }^{37}$. During development Ptch1 is preferentially expressed in the mesenchyme, whereas the Ptch2 homologue is co-expressed with Shh in the epithelium. ${ }^{38}$ Our data suggest that this differential expression of Ptch receptors is maintained into adulthood. In response to chronic injury, we found enhanced coexpression of Ptch2 along with Shh in PDG and in the ductal surface epithelium, whereas Ptch1 was expressed in the fibrotic stroma. Ptch2 expression and upregulation in the surface epithelium in vivo and in HPDE cells in vitro demonstrate that PDG-derived Shh can influence responsive target cells not only in PDG, but in the entire ductal epithelium, similarly as suggested for growth factor signaling. ${ }^{28}$ Whereas we focused on the epithelial 
effects of Hh signaling and their role in epithelial metaplasia and early carcinogenesis, paracrine stromal Hh activation ${ }^{35-37}$ via the Ptch1 receptor may represent a parallel and even predominant mechanism of $\mathrm{Hh}$ activation within the entire tissue. At present, the exact role of Hh signaling in the complexity of epithelial-mesenchymal interactions remains to be understood.

Although much work must still be done to confirm the role of PDG in protection, regeneration and cancer, it is clear that they represent a distinct gland-like compartment, principally located in the proximal ductal system, which has a distinct molecular signature and is different from the normal pancreatic ductal epithelium. PDG may thus provide a link between injury, Shh-activation, mucinous metaplasia and neoplasia and represent a possible cell of origin.

\section{Supplementary Material}

Refer to Web version on PubMed Central for supplementary material.

\section{Acknowledgments}

Grant support: This work was supported by grants from the German Research Foundation (STR 690/1-1) and the Surgery Foundation Heidelberg (Lautenschläger Scholarship) (O.S.), the Karin Grunebaum Cancer Research Foundation (D.E.R.), the Lustgarten Foundation for Pancreatic Cancer Research (RFP05-008), and the National Institutes of Health (K08DK71329, P50CA127003, and P01CA117969) (S.P.T.).

We thank Matthew Scott for the Ptch1-LacZ mouse, Ming-Sound Tsao for HPDE cells, Chris Wright for Pdx-1 antibody, Tetsuno Sudo for Hes-1 antibody, Samuel Ho for antibodies against mouse gastric mucins, and Victoria Petkova and Rebecca Stearns for assistance with RTq-PCR and SEM.

\section{Abbreviations}

$\begin{array}{ll}\text { PDG } & \text { pancreatic duct glands } \\ \text { PanIN } & \text { pancreatic intraepithelial neoplasia } \\ \text { CP } & \text { chronic pancreatitis } \\ \text { GI } & \text { gastrointestinal } \\ \text { PAS } & \text { periodic acid-Schiff's } \\ \text { SEM } & \text { scanning electron microscopy } \\ \text { Hh } & \text { hedgehog }\end{array}$

HPDE cells human pancreatic ductal epithelial cells

\section{Reference List}

1. Hruban RH, Adsay NV, Albores-Saavedra J, et al. Pancreatic intraepithelial neoplasia: a new nomenclature and classification system for pancreatic duct lesions. Am J Surg Pathol. 2001; 25:579-586. [PubMed: 11342768]

2. Strobel O, Dor Y, Alsina J, et al. In vivo lineage tracing defines the role of acinar-to-ductal transdifferentiation in inflammatory ductal metaplasia. Gastroenterology. 2007; 133:1999-2009. [PubMed: 18054571]

3. Guerra C, Schuhmacher AJ, Canamero M, et al. Chronic pancreatitis is essential for induction of pancreatic ductal adenocarcinoma by K-Ras oncogenes in adult mice. Cancer Cell. 2007; 11:291302. [PubMed: 17349585] 
4. Habbe N, Shi G, Meguid RA, et al. Spontaneous induction of murine pancreatic intraepithelial neoplasia (mPanIN) by acinar cell targeting of oncogenic Kras in adult mice. Proc Natl Acad Sci U S A. 2008; 105:18913-18918. [PubMed: 19028870]

5. De La OJ, Emerson LL, Goodman JL, et al. Notch and Kras reprogram pancreatic acinar cells to ductal intraepithelial neoplasia. Proc Natl Acad Sci U S A. 2008; 105:18907-18912. [PubMed: 19028876]

6. Jensen JN, Cameron E, Garay MV, et al. Recapitulation of elements of embryonic development in adult mouse pancreatic regeneration. Gastroenterology. 2005; 128:728-741. [PubMed: 15765408]

7. Taipale J, Beachy PA. The Hedgehog and Wnt signalling pathways in cancer. Nature. 2001; 411:349-354. [PubMed: 11357142]

8. Offield MF, Jetton TL, Labosky PA, et al. PDX-1 is required for pancreatic outgrowth and differentiation of the rostral duodenum. Development. 1996; 122:983-995. [PubMed: 8631275]

9. Sharma A, Zangen DH, Reitz P, et al. The homeodomain protein IDX-1 increases after an early burst of proliferation during pancreatic regeneration. Diabetes. 1999; 48:507-513. [PubMed: 10078550]

10. Taguchi M, Yamaguchi T, Otsuki M. Induction of PDX-1-positive cells in the main duct during regeneration after acute necrotizing pancreatitis in rats. J Pathol. 2002; 197:638-646. [PubMed: 12210084]

11. Esni F, Ghosh B, Biankin AV, et al. Notch inhibits Ptf1 function and acinar cell differentiation in developing mouse and zebrafish pancreas. Development. 2004; 131:4213-4224. [PubMed: 15280211]

12. Stanger BZ, Stiles B, Lauwers GY, et al. Pten constrains centroacinar cell expansion and malignant transformation in the pancreas. Cancer Cell. 2005; 8:185-195. [PubMed: 16169464]

13. Siveke JT, Lubeseder-Martellato C, Lee M, et al. Notch signaling is required for exocrine regeneration after acute pancreatitis. Gastroenterology. 2008; 134:544-555. [PubMed: 18242220]

14. Hebrok M, Kim SK, Melton DA. Notochord repression of endodermal Sonic hedgehog permits pancreas development. Genes Dev. 1998; 12:1705-1713. [PubMed: 9620856]

15. Thayer SP, di Magliano MP, Heiser PW, et al. Hedgehog is an early and late mediator of pancreatic cancer tumorigenesis. Nature. 2003; 425:851-856. [PubMed: 14520413]

16. Strobel O, Dor Y, Stirman A, et al. beta cell transdifferentiation does not contribute to preneoplastic/metaplastic ductal lesions of the pancreas by genetic lineage tracing in vivo. Proc Natl Acad Sci U S A. 2007; 104:4419-4424. [PubMed: 17360539]

17. Furukawa T, Duguid WP, Rosenberg L, et al. Long-term culture and immortalization of epithelial cells from normal adult human pancreatic ducts transfected by the E6E7 gene of human papilloma virus 16. Am J Pathol. 1996; 148:1763-1770. [PubMed: 8669463]

18. Ouyang H, Mou L, Luk C, et al. Immortal human pancreatic duct epithelial cell lines with near normal genotype and phenotype. Am J Pathol. 2000; 157:1623-1631. [PubMed: 11073822]

19. Kim GE, Bae HI, Park HU, et al. Aberrant expression of MUC5AC and MUC6 gastric mucins and sialyl Tn antigen in intraepithelial neoplasms of the pancreas. Gastroenterology. 2002; 123:10521060. [PubMed: 12360467]

20. Sessa F, Bonato M, Frigerio B, et al. Ductal cancers of the pancreas frequently express markers of gastrointestinal epithelial cells. Gastroenterology. 1990; 98:1655-1665. [PubMed: 1692551]

21. Maitra A, Adsay NV, Argani P, et al. Multicomponent analysis of the pancreatic adenocarcinoma progression model using a pancreatic intraepithelial neoplasia tissue microarray. Mod Pathol. 2003; 16:902-912. [PubMed: 13679454]

22. van den Brink GR, Hardwick JC, Nielsen C, et al. Sonic hedgehog expression correlates with fundic gland differentiation in the adult gastrointestinal tract. Gut. 2002; 51:628-633. [PubMed: 12377798]

23. Prasad NB, Biankin AV, Fukushima N, et al. Gene expression profiles in pancreatic intraepithelial neoplasia reflect the effects of Hedgehog signaling on pancreatic ductal epithelial cells. Cancer Res. 2005; 65:1619-1626. [PubMed: 15753353]

24. MCMINN RM, KUGLER JH. The glands of the bile and pancreatic ducts: autoradiographic and histochemical studies. J Anat. 1961; 95:1-11. [PubMed: 13774143] 
25. Bock P. Pancreatic duct glands. I. Staining reactions of acid glycoprotein secret. Acta Histochem. 1978; 61:118-126. [PubMed: 79293]

26. Geleff S, Bock P. Pancreatic duct glands. II. Lectin binding affinities of ductular epithelium, ductular glands, and Brunner glands. Histochemistry. 1984; 80:31-38. [PubMed: 6698813]

27. Bock P, Geleff S. Pancreatic duct glands. III. Morphology of secretory epithelium and endoepithelial glands. Z Mikrosk Anat Forsch. 1984; 98:857-872. [PubMed: 6528718]

28. Wright NA, Poulsom R, Stamp GW, et al. Epidermal growth factor (EGF/URO) induces expression of regulatory peptides in damaged human gastrointestinal tissues. J Pathol. 1990; 162:279-284. [PubMed: 2290113]

29. Taguchi M, Otsuki M. Co-localization of nestin and PDX-1 in small evaginations of the main pancreatic duct in adult rats. J Mol Histol. 2004; 35:785-789. [PubMed: 15609091]

30. Fendrich V, Esni F, Garay MV, et al. Hedgehog signaling is required for effective regeneration of exocrine pancreas. Gastroenterology. 2008; 135:621-631. [PubMed: 18515092]

31. Li C, Heidt DG, Dalerba P, et al. Identification of pancreatic cancer stem cells. Cancer Res. 2007; 67:1030-1037. [PubMed: 17283135]

32. Lee CJ, Dosch J, Simeone DM. Pancreatic cancer stem cells. J Clin Oncol. 2008; 26:2806-2812. [PubMed: 18539958]

33. Silberg DG, Furth EE, Taylor JK, et al. CDX1 protein expression in normal, metaplastic, and neoplastic human alimentary tract epithelium. Gastroenterology. 1997; 113:478-486. [PubMed: 9247467]

34. Wong NA, Wilding J, Bartlett S, et al. CDX1 is an important molecular mediator of Barrett's metaplasia. Proc Natl Acad Sci U S A. 2005; 102:7565-7570. [PubMed: 15894614]

35. Bailey JM, Swanson BJ, Hamada T, et al. Sonic hedgehog promotes desmoplasia in pancreatic cancer. Clin Cancer Res. 2008; 14:5995-6004. [PubMed: 18829478]

36. Yauch RL, Gould SE, Scales SJ, et al. A paracrine requirement for hedgehog signalling in cancer. Nature. 2008; 455:406-410. [PubMed: 18754008]

37. Tian H, Callahan CA, DuPree KJ, et al. Hedgehog signaling is restricted to the stromal compartment during pancreatic carcinogenesis. Proc Natl Acad Sci U S A. 2009; 106:4254-4259. [PubMed: 19246386]

38. Motoyama J, Takabatake T, Takeshima K, et al. Ptch2, a second mouse Patched gene is coexpressed with Sonic hedgehog. Nat Genet. 1998; 18:104-106. [PubMed: 9462734] 


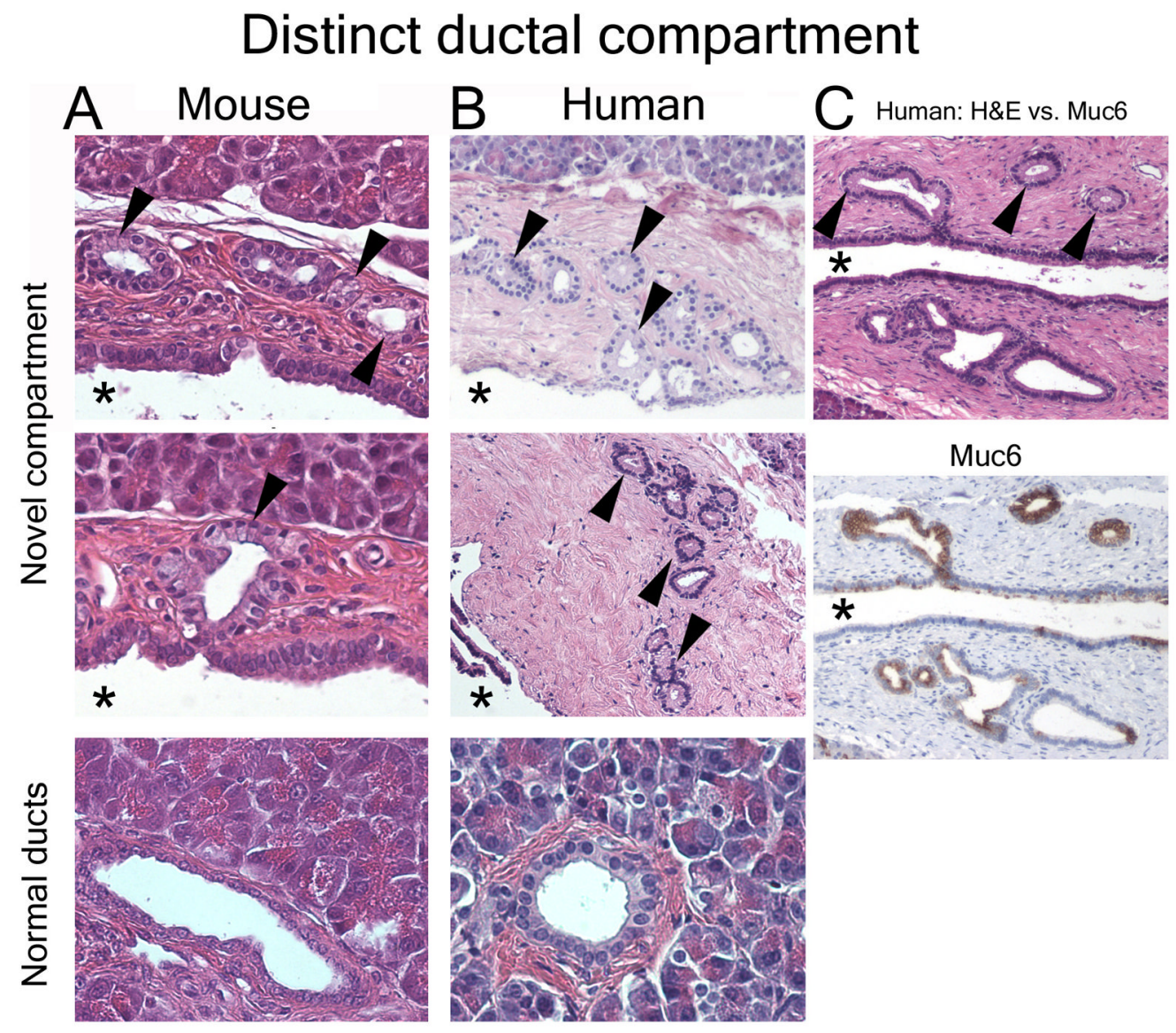

Figure 1.

Morphologically distinct ductal compartment. Normal mouse (A) and human (B) pancreas. Cells with abundant supranuclear cytoplasm and basally located nuclei (arrowheads) are located in outpouches/small branches (arrowheads) within the ductal wall mesenchyme. This compartment is morphologically distinct from the epithelial lining of the adjacent main lumen (asterisk) and peripheral ducts of comparable size (lower panels). (C) Serial sections reveal that the novel compartment has unique molecular features, such as expression of Muc6 (brown). 

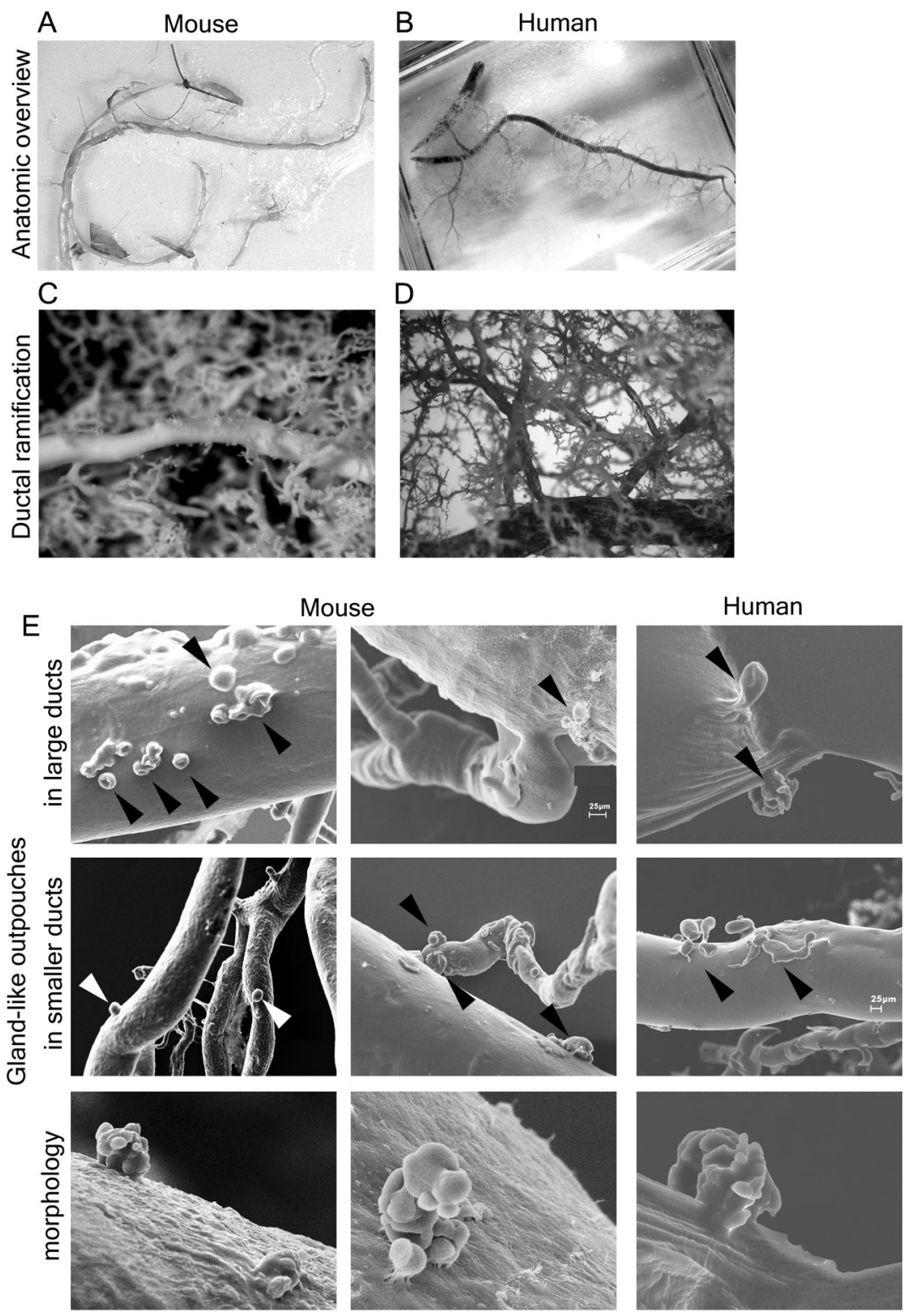

Figure 2.

Corrosion casts reveal that ducts have blind-ending outpouches: pancreatic duct glands. (A, B) Overviews show complete corrosion casts of the ductal system of (A) mouse and (B) human. (C, D) Light microscopy demonstrates hierarchical ramification of the ductal system rather than multiple small branches of larger ducts. (E) SEM reveals that pancreatic ducts have small gland-like outpouches, often located near branching points (arrowheads). They are predominantly found in large ducts (upper panels) but can be observed in small ducts (mid panels). These glands can appear as single outpouches or exhibit a complex arrangement of several sac-like dilations (lower panels). 


\section{Response to chronic injury}
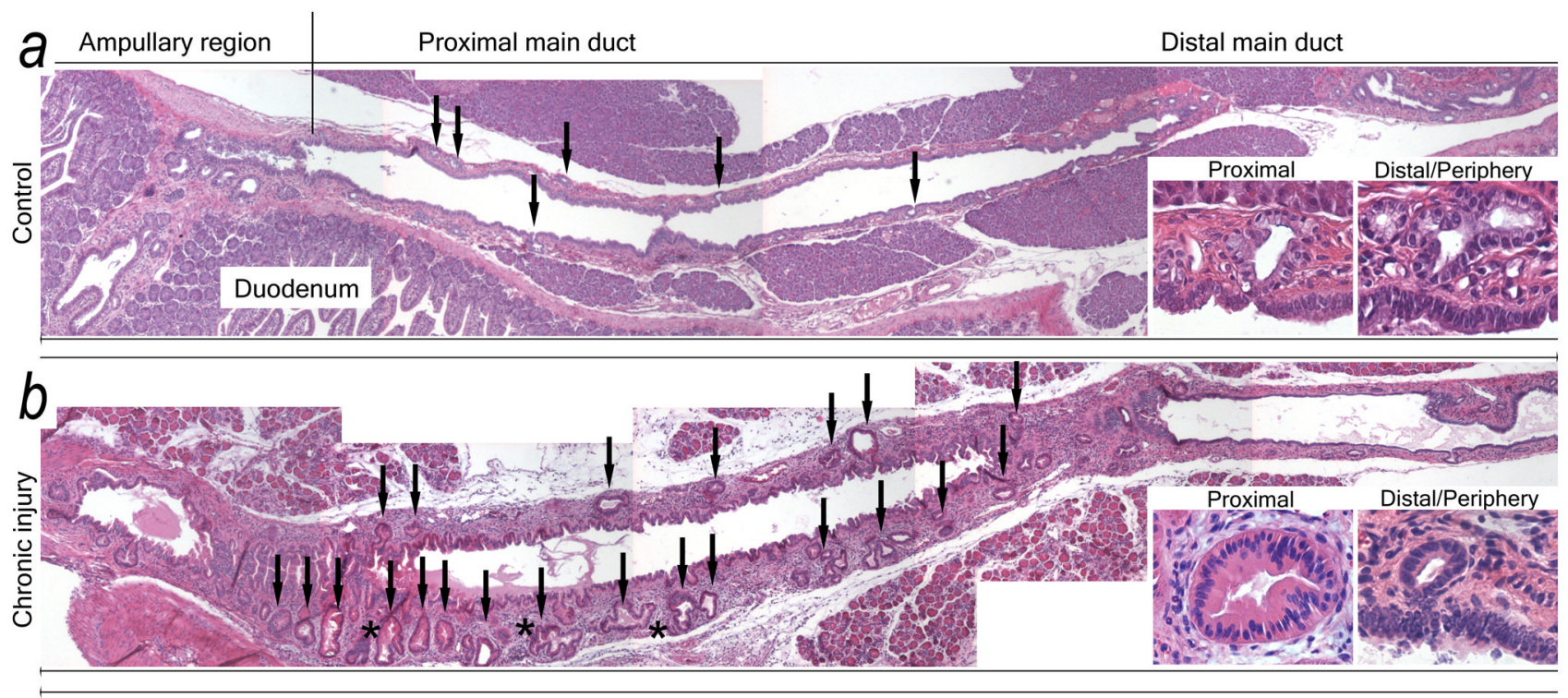

\section{Response to chronic injury}
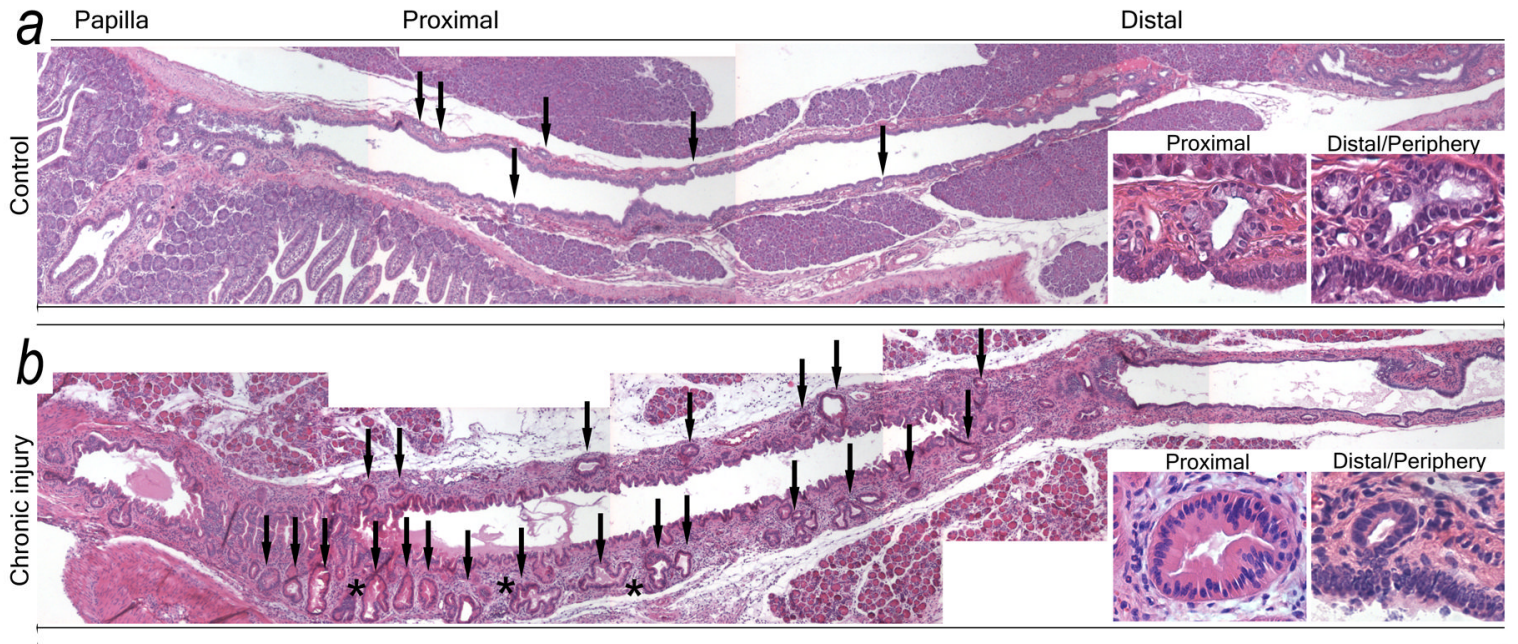

Figure 3.

PDG undergo hyperplasia in response to chronic injury. Overviews of the proximal ductal systems of a control animal (A) and an animal with chronic injury and metaplasia (B). (A) The normal pancreas has few, small PDG (arrows) with a regular, single-layer lining of mucinous appearance (insets) in a thin ductal mesenchyme. (B) In chronic injury PDG significantly increase in both number and size (arrows). PDG exhibit hyperplasia, a complex morphology (asterisk) and are lined by a less regular epithelium with several layers and papillations (insets). Changes are more pronounced in proximal PDG. The ductal mesenchyme is thickened. 


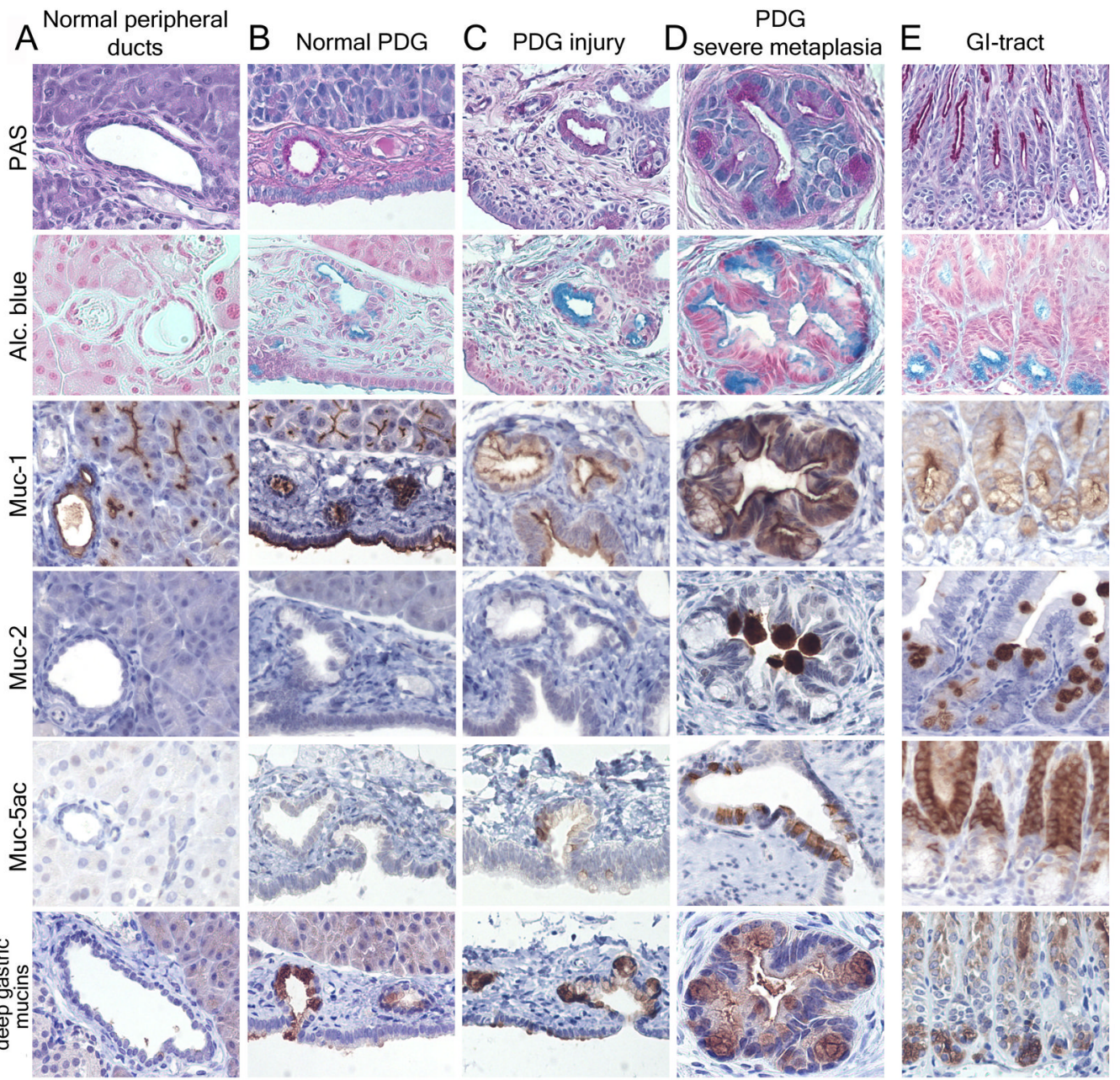

Figure 4.

Mouse pancreas: PDG retain GI mucins and are a source of GI mucinous metaplasia. (A) Normal peripheral pancreatic ducts have a cuboidal to low columnar epithelium with low expression of $\mathrm{PAS}^{+}$mucins (magenta) and Muc-1, but are Alcian blue ${ }^{-}$. (B) PDG contain a distinct epithelium with $\mathrm{PAS}^{+}$and Alcian blue ${ }^{+}$(turquoise) mucins. PDG, but not the lining of the main lumen (below), express mucins normally found in the deep gastric mucosa (low panels) (GI tract in E). (C, D) In chronic injury, PDG hypertrophy, along with increased mucin expression and morphologic atypia. Gastric mucins are upregulated (lower two rows). Muc5ac is frequently, Muc2 rarely expressed. This results in a metaplastic phenotype resembling the pyloric region $(\mathrm{E})$, rather than normal pancreatic ducts $(\mathrm{A})$. 

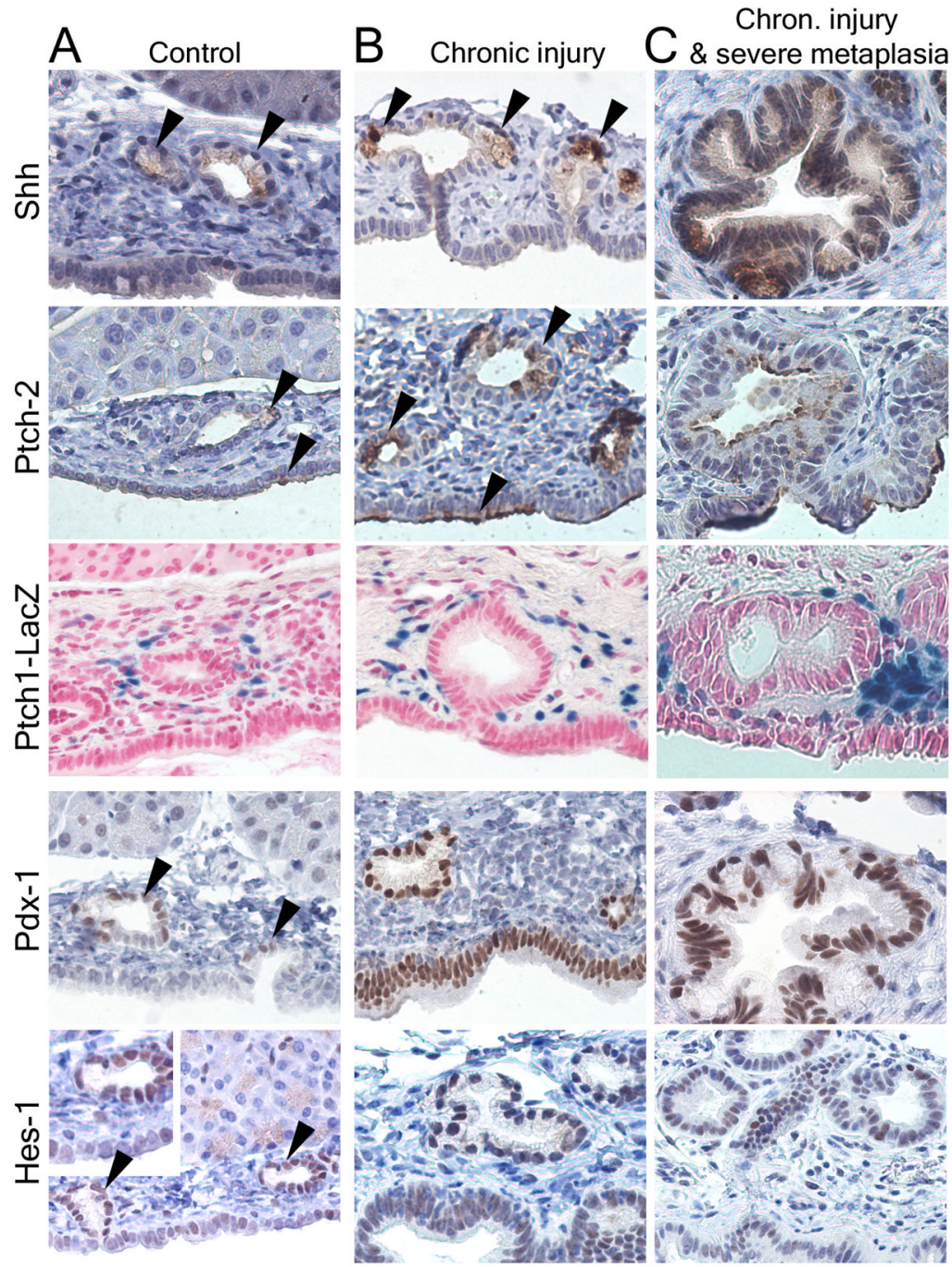

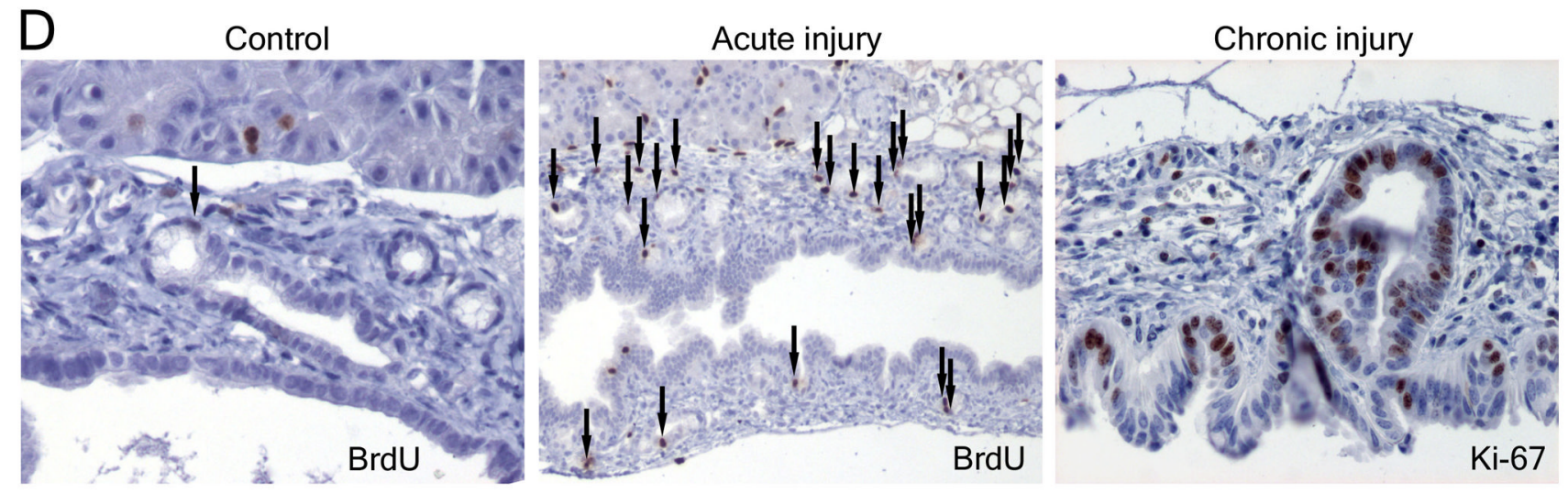

Proliferative index

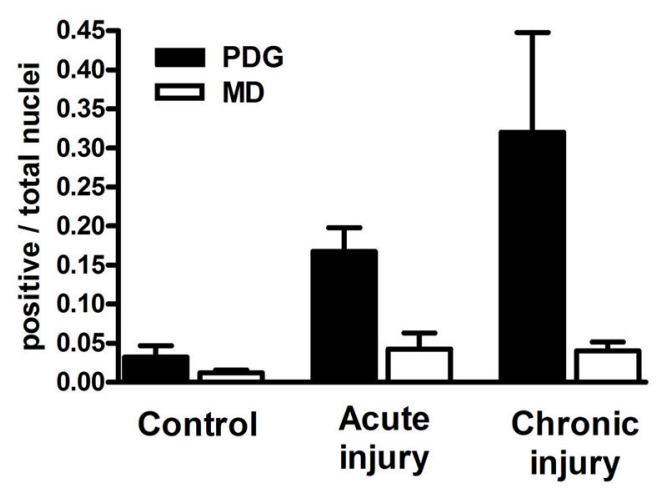

Figure 5.

PDG are a preferential site of expression of developmental factors and of proliferation. (A) In the normal state, Shh is expressed at a low level specifically in PDG (arrowheads), but not in the luminar epithelium. The receptor Ptch2 is co-expressed with Shh in PDG and additionally in some cells of the ductal surface epithelium (arrowheads); Ptch1 is expressed in the mesenchyme around PDG. Pdx-1 is expressed predominantly in PDG (arrowheads) but can be identified in the ductal epithelium. Hes-1 is expressed predominantly in PDG within large ducts (arrowheads) but can be identified throughout the ductal epithelium. (B) In response to chronic injury, all these markers appear upregulated. Shh remains specific to mucinous cells within PDG. Ptch2 is expressed in PDG but expanded in surface epithelium (arrowheads); Ptch1 is generalized in the ductal mesenchyme. Expression of Pdx-1 and Hes-1 is expanded or generalized in the ductal epithelium. (C) In severe metaplasia and atypia these changes are more pronounced. Shh remains specific for the mucinous epithelium. Pdx-1 and Hes-1 are expanded to the surface epithelium, but remain strongly expressed in the deeper epithelium. (D) In response to injury, proliferation (BrdU incorporation) in large ducts is predominantly located to PDG (arrows). In chronic injury and metaplasia, expression of the proliferation marker Ki-67 is identified predominantly in PDG and the apex of mucosal folds. MD: Main duct epithelial lining. 


\section{Peripheral presence of PDG compartment}

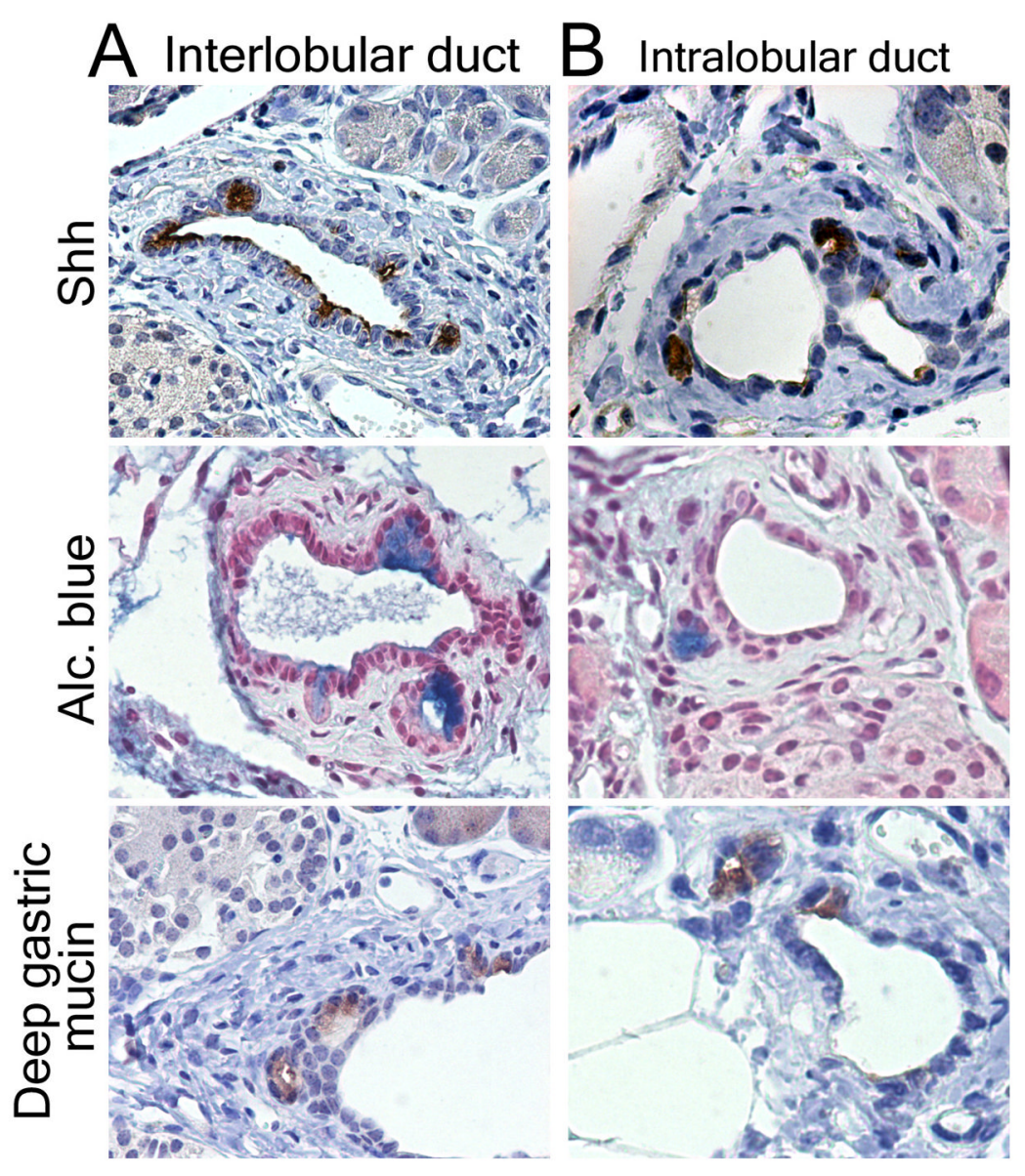

Figure 6.

The PDG compartment exists in peripheral ducts. In chronic injury Shh, Alcian blue and Muc6 identify the PDG-compartment in the mesenchyme of interlobular (A) and small intralobular (B) ducts. 

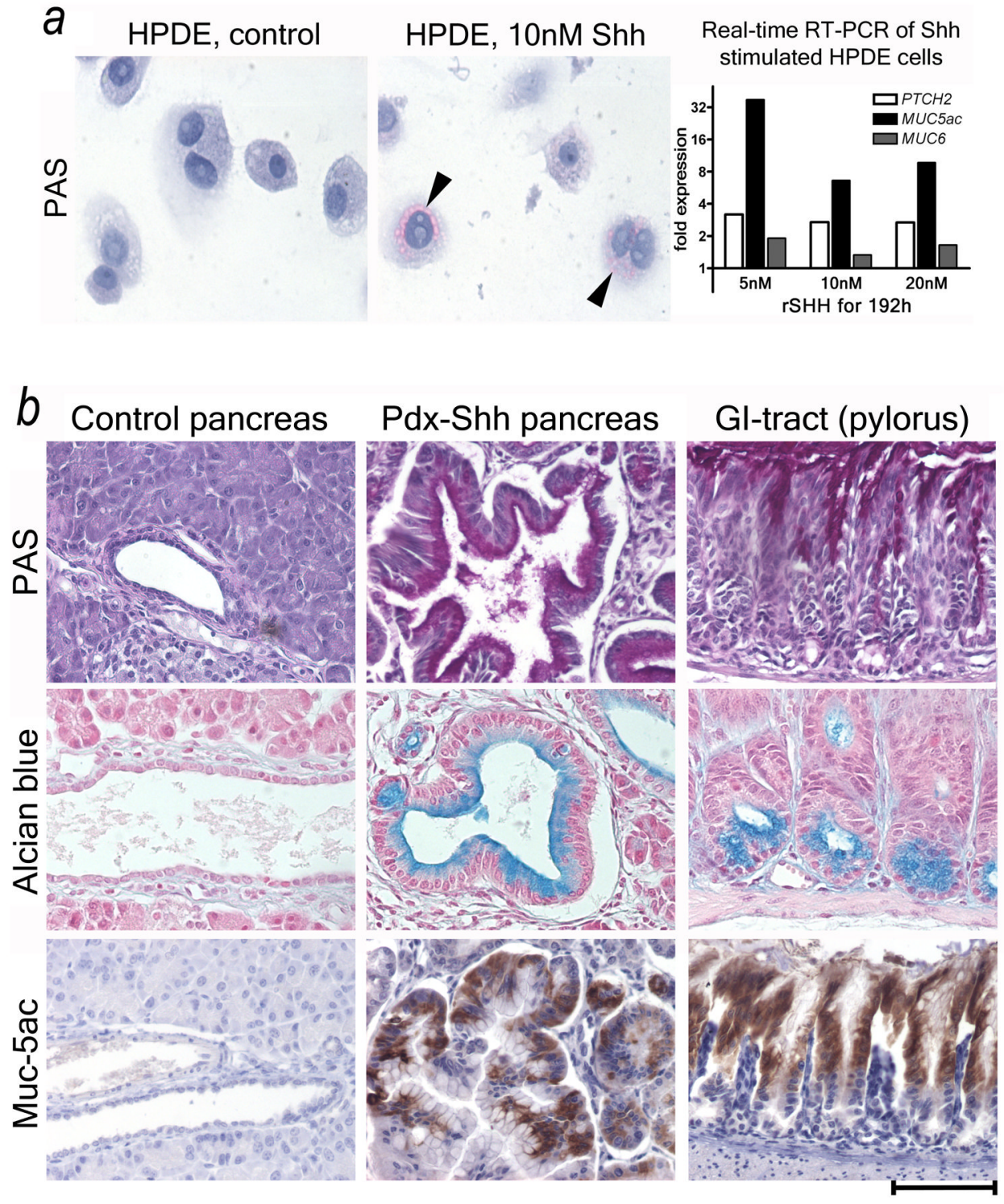

Figure 7.

Shh misdirects the pancreatic ductal epithelium toward a GI mucinous metaplasia. (A) Shh exposure results in enhanced mucin expression (PAS: magenta, arrowheads) in HPDE cells. Real-time quantitative RT-PCR reveals that HPDE cells are Hh target cells expressing the receptor $P T C H 2$. In response to Shh exposure the pathway is activated (PTCH2 upregulation) along with upregulation of gastric mucins (MUC5ac, MUC6). (B) Transgenic misexpression of Shh in Pdx-Shh mice results in a GI phenotype of pancreatic ducts with expression of $\mathrm{PAS}^{+}$(magenta) and Alcian blue ${ }^{+}$mucins, including Muc5ac. Scale bars indicate $100 \mu \mathrm{m}$. 


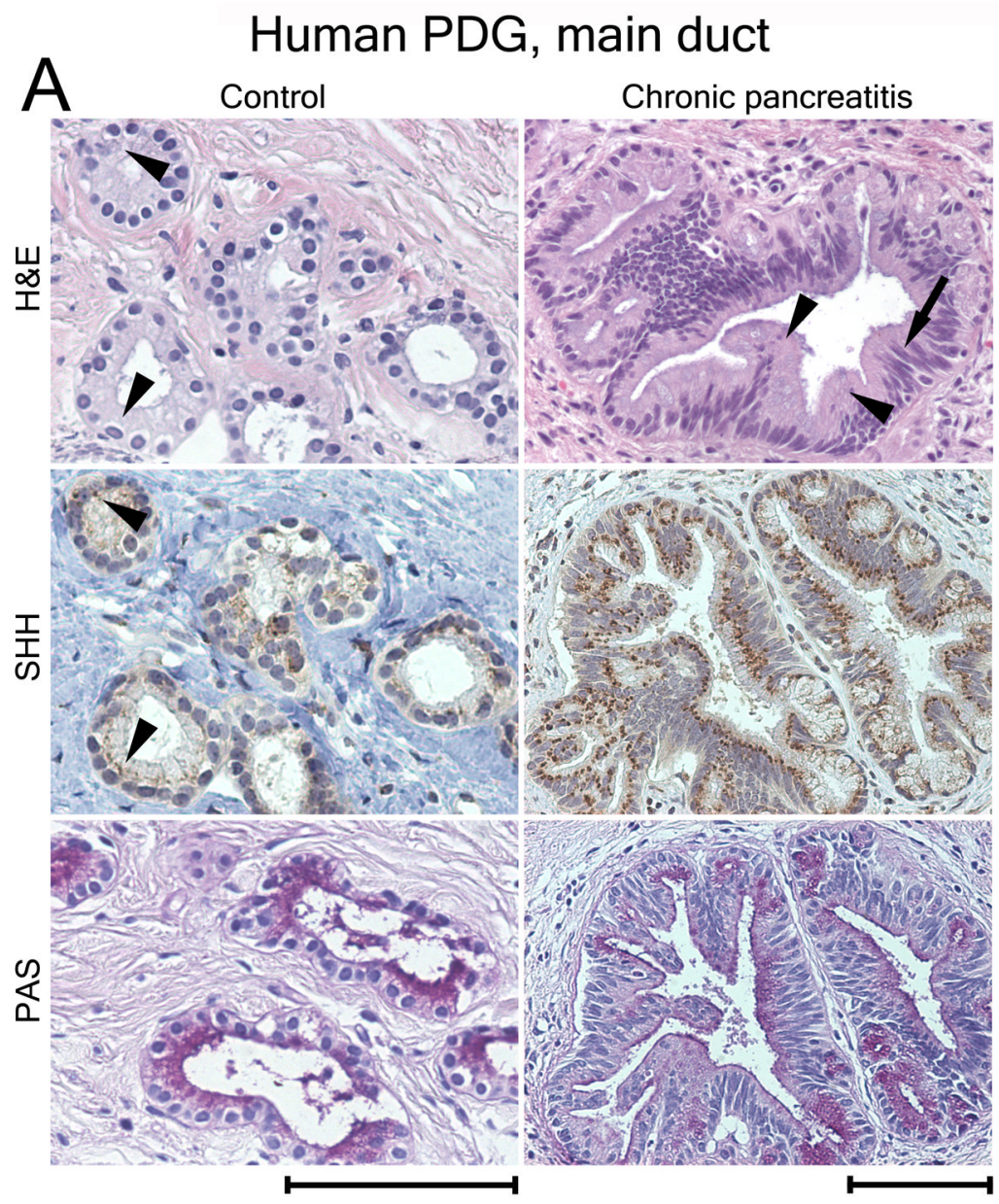




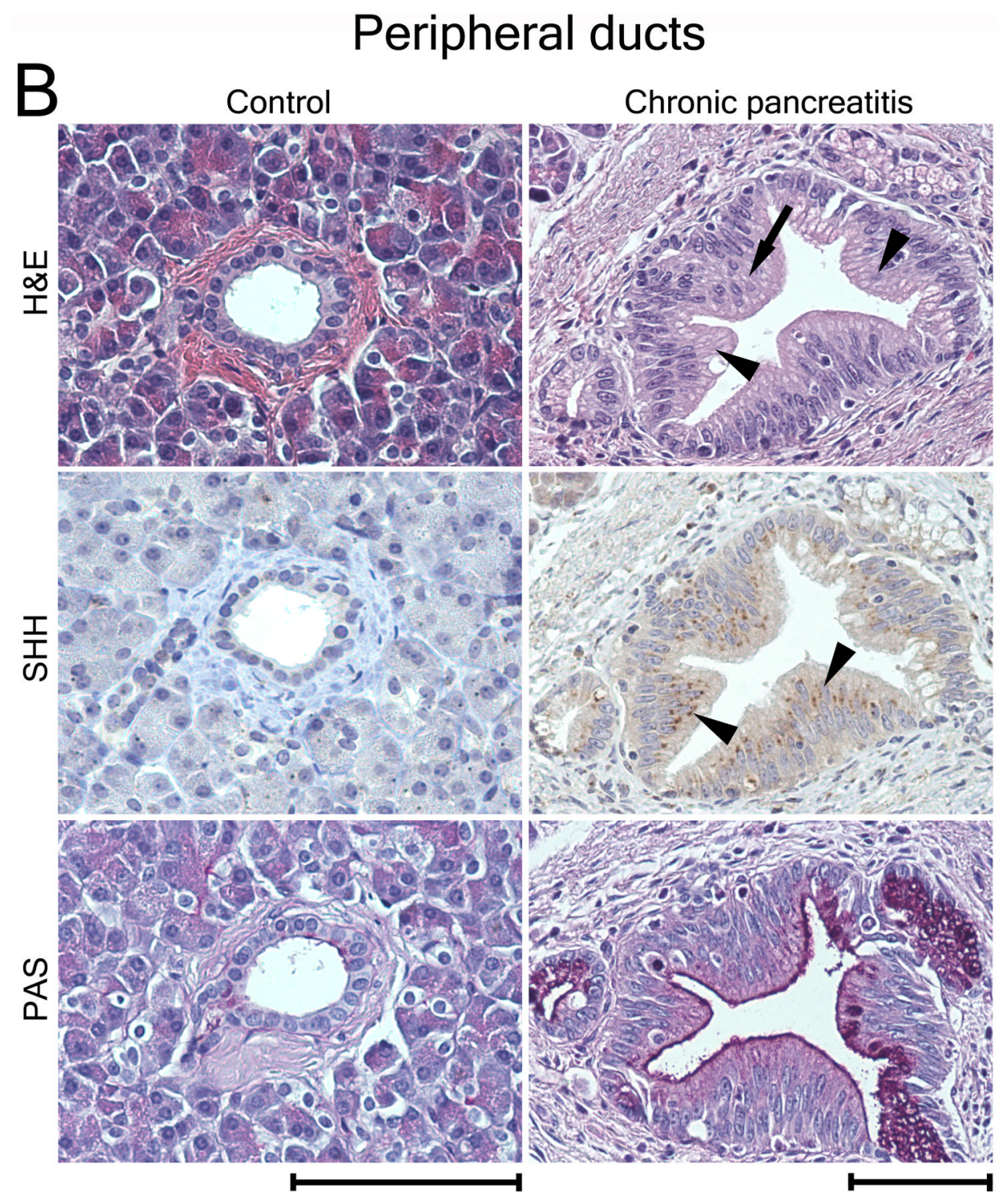

C

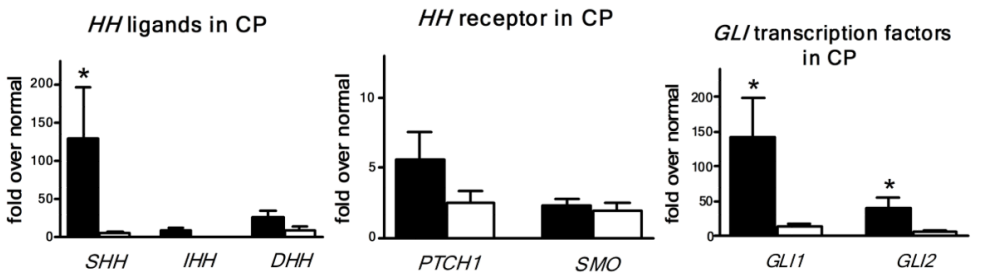

Figure 8.

SHH is expressed in human PDG and upregulated in metaplasia. (A) PDG of the main duct. Control: SHH is expressed at a low level in PDG (arrowheads). PAS staining (magenta) identifies co-expression of mucins. $\underline{\mathrm{CP}}$ : H\&E reveals hypertrophic outpouches/branches exhibiting papillary formations (arrowheads) and pseudo-stratified nuclei (arrow), features of PanIN. SHH is upregulated, identified by brown supranuclear granular staining. PAS reveals enhanced mucin expression. (B) Control: Peripheral ducts have cuboidal epithelium 
without Shh expression and with minimal expression of mucins. $\underline{\text { CP: Atypical peripheral }}$ ducts with PanIN features (arrow, arrowheads) express SHH (arrowheads) along with increased mucin expression. Scale bars indicate $100 \mu \mathrm{m}$. (C) Expression of HH pathway genes in CP shown as -fold expression over normal pancreata. Shh and the effectors Gli-1 and Gli-2 are significantly upregulated. Receptor genes $P T C H 1$ and $S M O$ are upregulated to a lesser extent. Comparison of expression levels in main duct tissue (black bars) vs. peripheral parenchyma (white bars) reveals that HH pathway activation is mainly localized to the proximal ductal system. Error bars indicate S.E.M. *, P $<0.05$. 